\title{
The impact of training on the views and knowledge of prospective Cruse counsellors
}

\author{
David A. Alexander, David Le Poidevin, Mairead Lobban and Mary Muir
}

\begin{abstract}
Fow would challenge the view that the contribution made by Cruse to the wellare of the bereoved is a very important one. Much effort is put into the training of Cruse counsellors but litile is known about the impact of this training. An ascessment of 30 prospective counsellors by means of questionnaires and 'clinical' vignettes to assess their knowledge of and attitudes to vorious motters pertaining to grief and bereovement is reported. While the results are encouraging in many respects, they atso highlight areas of ignorance and bias which seem reatstont to the influence of training.
\end{abstract}

Much has been written about bereavement (Alexander, 1988), and considerable effort has gone into describing the effects of bereavement and assessing how best to help the bereaved (e.g. Raphael, 1984; Osterweiss et al 1984; Parkes, 1986). Help is available from many agencies, lay and professional, but in the United Kingdom the only national network of care for the bereaved is provided by Cruse. The standard of Cruse counsellors is therefore of considerable importance. In 1986 a Cruse Working Party exhorted its branches to improve the quality of training offered. Unfortunately, little is known about the impact of this training in terms of purveying accurate information and of achieving satisfactory attitudes and levels of skill. This study of the intake of two annual Cruse courses in Aberdeen provides some insight into the impact of Cruse training. The course (run by accredited counsellors and a consultant psychotherapist) comprises didactic sessions, small group discussion, case presentations, role playing and personal testimonies by bereaved individuals. The topics covered are theories and descriptions of normal and pathological grief in children and adults as well as different counselling techniques and approaches.

\section{The study}

Thirty individuals from an intake of 32 trainees over a two year period agreed to take part in the study. The respondents included four men and 26 women; nine were widowed, 17 were married, two were single and two were divorced or separated.

Before and after their course trainees completed a bereavement questionnaire (which comprised 24 Likert items on grief, mourning and bereavement) and a characteristics questionnaire in which the trainees had to evaluate the helpfulness of 15 counsellor qualities (e.g. high intelligence, gender, sombre manner and warmth). In addition, the respondents were given five vignettes of different instances of bereavement (e.g. death by suicide, death without a body and death after a long and painful illness). The respondents were required in each case to rate the helpfulness of 16 interventions which included giving advice, referral to a psychiatrist, the use of drugs and the expression of feelings.

\section{Findings}

Space limits the presentation of the data to a distillate of some of the more salient findings, but fuller details are available from the senior author.

Some reassurance can be derived from the finding that even before their training these trainees displayed some sound basic knowledge of and views about bereavement and its management. Using the 24 items of the bereavement questionnaire nine trainees obtained a statistically significant difference between the two assessments. All of these were in the 'correct' direction judged on the basis of well-established empirical findings and principles. 
However, complacency is not justified. There were pockets of ignorance and bias which appeared to be impervious to the impact of the course. For instance, after the course, five trainees still believed that public mourning rituals retard the grieving process; five believed counselling could do no harm; four did not accept the deleterious effect bereavement may have on physical health; two did not believe a stillbirth may provoke a grief reaction, and one believed that delayed grief is a sign of good adjustment and that a missing body has no bearing on the outcome of a bereavement. There were, in addition, two trainees who considered that those bereaved by the suicide of their loved ones characteristically adjust quickly. Nor was it reassuring to note that ten were adamant that night sedation has no role to play in normal grief.

There were also areas of uncertainty. After the course, half of the trainees were still uncertain whether widowers are at a greater risk of suicide than are widows, and about a quarter were not sure if there is a relationship between socio-economic circumstances and the outcome of bereavement. The course also failed to convince 17 trainees that previous mental illness is likely to be a poor prognostic indicator, and another three still believed that grieving is usually completed after three months.

\section{Counsellor characteristics}

In general, how these trainees evaluated certain counsellor characteristics was not significantly affected by their course. Consistently before and after the course the majority dismissed the relevance of high intelligence, strong religious beliefs, marital status, gender and age, although one trainee believed that it is unhelpful to be a female counsellor, and two thought being married was unhelpful. Nearly all, however, endorsed the value of the counsellor being warm, open, reassuring and confident. (It remains a puzzle however why 'openness' and 'warmth' should be viewed by two trainees and one trainee respectively as most unhelpful.)

The factors most frequently identified as most unhelpful were having a sombre or detached manner and having a fear of death. Four trainees also considered that having strong religious beliefs is unhelpful.

\section{Training vignettes}

Vignettes are not the ideal method of assessing how trainees would in reality deal with bereaved clients, but they do at least give some indication as to what general strategies and techniques they would be likely to use when faced with different cases of bereavement. Out of the 80 before and after comparisons, training had a statistically significant effect on 13 of them in terms of altering what trainees claimed they would do after training compared with what they alleged would be their decision before the course. However, apart from the use of self disclosure, there was no pattern to these changes. After the course, in four out of the five vignettes the trainees were significantly less likely to regard self-disclosure as helpful. There were some other interesting findings. First, certain interventions were consistently seen as helpful or unhelpful over the five vignettes. To display understanding, recommending attendance at social groups and promoting Cruse's social activities were popular choices by the trainees, and the provision of literature on bereavement was also a highly rated intervention. The least popular choice was to discourage in counselling talk of the client's past. Second, the only intervention which underwent a statistically significant change over the two assessment periods was discussion of the client's upbringing. Before the course it was ranked as the tenth most helpful intervention; after the training it rose to the fourth most popular. Third, psychiatric referral was not often regarded as helpful, not even in the vignette which involved a bereaved middleaged woman with a long history of depression and who was described at interview as displaying likely signs of depression. Only 16 of the trainees would have considered referral for this lady. Finally, asking about the use of alcohol and drugs by the bereaved were not generally seen as helpful. Even with the vignette which described a widower with a marked history of alcohol abuse only nine out of 30 trainees after the course felt it would have been helpful to have asked their client about his alcohol consumption.

\section{Comment}

The fact that well-motivated lay persons give up so much time to help the bereaved is laudable, and this paper does not question 
their motivation or their integrity. However, as the body of well-established facts about bereavement continues to grow, it is reasonable to ask what would constitute 'core' knowledge and essential attitudes among Cruse counsellors. There is no reason to assume the trainees on these two courses are atypical or that the courses were materially different from the kind of course run nationally by Cruse. This study raises important questions therefore about training standards and their achievement.

\section{Acknowledgements}

The authors are grateful to the trainee counsellors who completed these questionnaires, and to David Hunter, and Sybil McLeod for the careful collation and analysis of the data.

\section{References}

AlEXANDER. D. A. (1988) Bereavement and the management of grief. British Journal of Psychiatry, 163, 860-864.

OSTERWEIS, M. SOLOMON. F. \& GREEN, M. (1984) Bereavement Reactions. Consequences and Care. Washington, DC: National Academic Press.

PARKES, C. M. (1986) Bereavement: studies of grief in adult life. (2nd edition) London: Tavistock.

RAPHAEL, B. (1984) The Anatomy of Bereavement. London: Hutchinson.

*David A. Alexander, Professor of Mental Health, Medical School, Foresterhill, Aberdeen AB9 2ZD; David Le Poidevin, Consultant Psychotherapist, Mairead Lobban, Registrar, and Mary Muir, Consultant Psychiatrist, Royal Cornhill Hospital, Aberdeen AB9 2ZH

*Correspondence

\section{Are you an expert witness?}

Solicitors looking for expert witnesses turn to the Law Society's Expert Witness Telephone Enquiry Service and to the Directory of Expert Witnesses.

If you have done some expert witness work in the past and would like to be included in either the Directory or the referral service, please contact:

The Project Manager, Law Society Directory of Expert Witnesses, FT Law and Tax, 21-27 Lamb's Conduit Street, London WC1N 3NJ. (Fax: 0171831 8119) 